\title{
Izabel dos Santos: fazendo história na história da enfermagem brasileira*
}

\author{
IZABEL DOS SANTOS: A HISTORY INSIDE BRAZILIAN NURSING HISTORY
}

IZABEL DOS SANTOS: UNA HISTÓRIA DENTRO DE LA HISTÓRIA DE LA ENFERMERÍA BRASILEÑA

\section{Izabel dos Santos ${ }^{1}$}

* Texto resultante de
entrevista concedida
a Rosa Maria Godoy
Serpa da Fonseca e
Emiko Yoshikawa
Egry, Professoras
Titulares do Departa-
mento de Enferma-
gem em Saúde Cole-
tiva da Escola de
Enfermagem da
Universidade de São
Paulo e consultoras
do Sistema de Certi-
ficação de Compe-
tências do Projeto de
Profissionalização
dos Trabalhadores da
Área de Enfermagem
- PROFAE - Ministé-
rio da Saúde.
1 Enfermeira aposen-
tada pelo Ministério
da Saúde. Consul-
tora do Projeto de
Profissionalização
dos Trabalhadores da
Área de Enfermagem
do Departamento de
Gestão da Educação
na Saúde do
Ministério da Saúde.
(PROFAE/DEGES/MS)

\section{APRESENTAÇÃO}

A cidade: Brasília.

O dia: 29 de julho de 2007, uma ensolarada tarde de domingo. Apesar de inverno, o ar morno incita as pessoas a conversar.

O tema da entrevista: Desafios da formação em enfermagem para a saúde coletiva.

O testemunho: uma das histórias mais vibrantes da formação de recursos humanos de enfermagem de nível médio no Brasil.

A entrevistada: Izabel dos Santos - mulher, negra, enfermeira, comunista, pioneira na contestação das desigualdades e iniqüidades, inconformada diante da assistência de enfermagem não condizente com as necessidades de saúde da população, pelo desinteresse na qualificação dos profissionais de enfermagem de nível médio.

Nasceu em Pirapora, município localizado ao norte de Minas Gerais, às margens do Rio São Francisco, na madrugada do dia 07 de março de 1927. O mapa astral do dia do seu nascimento indica características que iriam marcar sua vida. O Sol em Peixes e a Lua em Touro garantiriam um caráter firme e decidido. $\mathrm{O}$ ascendente em Capricórnio já desenhava uma existência na qual o temperamento seria muito importante, projetando uma imagem de ambição, força de vontade, coerência e perseverança, propensa a buscar poder material, social e também político. Capricorniana por ascendência, a vida sempre lhe constituiria um desafio, que a obrigaria a utilizar todos os recursos de que disporia para triunfar. Devido à sua trajetória de lutas cairia nas boas graças de pessoas importantes. Sua mente seria racional e naturalmente cética. Sua enorme disposição para o trabalho lhe permitiria enfrentar obstáculos e frustrações, sem jamais se render a eles.

Confirmam tais tendências, entre outras, a grande obra da sua vida: tornar os profissionais de nível médio de enfermagem sujeitos sociais capazes de trabalhar com dignidade e competência. Na experiência acumulada em 80 anos de vida e mais de 50 de enfermagem - atua até hoje - nunca lhe faltou noção do tamanho do desafio. Suas palavras iniciais o confirmam:

Foi uma tarefa terrível de complexa, dolorosa, demorada, ter que enfrentar toda a hegemonia estruturada, a concepção de escola, a concepção de educação. Tive que quebrar tudo isso. Esta história já tem mais de 20 anos... 
Com vocês, as palavras sábias e realistas de Izabel dos Santos, trazidas até nós, pela sua própria vontade, por Ena de Araújo Galvão. ${ }^{\text {(a) }}$

\section{COMO TUDO COMEÇOU(b)}

Comecei a trabalhar na proposta de formação para o nível médio de enfermagem na década de

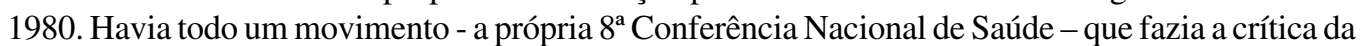
qualidade dos recursos humanos em saúde. Junto com isto, havia também um grande desejo de mudança. Todo mundo estava eufórico com a derrubada da ditadura e queria participar. Todo mundo acreditava que o Brasil podia ser melhor. O contexto era favorável.

Por outro lado, o desafio era muito grande: construir uma nova proposta de formação de recursos humanos de enfermagem de nível médio. Por que? Porque o prazo dado pela lei que exigia a qualificação dos atendentes estava para terminar e a partir daí todos os trabalhadores não qualificados estariam fora da lei. Havia ameaça de desemprego em massa. Os sindicatos estavam muito preocupados e o boato era de que em São Paulo já haviam prendido várias pessoas.

Mas se tudo isso era contexto, a minha ação começou mesmo quando uma atendente me fez a seguinte pergunta: É possível fazer um curso de auxiliar de enfermagem sem sair daqui? Ela trabalhava num hospital do interior do país. Então falei: Bem, não sei, mas vou ver, vou consultar, vou tentar. Ali foi que realmente tudo começou.

Havia um contingente muito grande de gente para se formar. Na época, já se estimava em 150 mil. O número de atendentes era igual ao número de médicos. Eram o mais qualificado e o menos qualificado em números iguais. Só que o atendente desqualificava o trabalho médico.

Sem esquecer a exigência da lei, eu saí procurando o que poderia ser feito. Na época, eu fazia parte de um grupo interministerial que estava preocupado em adequar recursos humanos das diversas áreas. Na saúde, a questão era formular políticas de RH para implementar o que depois viria a ser o SUS. A saúde sempre improvisou na área do nível médio. A desculpa era que não tinha gente pronta. Mas eu acho que não era isso só. Tinha também toda uma improvisação e uma racionalidade econômica para fazer saúde com o recurso que era mais barato, porque ficava mais barato trabalhar com atendentes. Quanto maior a qualificação, mais teria que pagar por isto. Pessoal mais qualificado custaria mais caro.

Como já disse, a mudança na lei foi a mola propulsora, o que acelerou a necessidade de qualificação, mas já havia crítica sobre a qualidade dos recursos humanos que se tinha na enfermagem, tanto do ponto de vista da competência técnica, como do saber-ser profissional. Só que era uma crítica muito vaga, estava mais no discurso da sociedade.

E aí, eu comecei a pensar o que fazer. Tinha uma moça que era professora de matemática na Argentina e estava aqui fazendo um curso de pós-graduação (mestrado ou doutorado, não me lembro bem) na área de educação. Ela estava interessada em análise de discurso. Eu não sabia o que era isso, mas me perguntei: Será que isso tem alguma coisa a ver comigo? Vou conversar com ela. Ela falou que na França tinha um grupo que trabalhava com pessoas da periferia de Paris que tinha desenvolvido uma metodologia própria para trabalhar com esse povo. Eu já tinha percebido que para trabalhar com pessoal de nível médio, o desafio também seria metodológico. Porque eles tinham déficits: eram desescolarizados, não sabiam pensar, não sabiam ler o contexto. Na época, já tinha também o discurso político de desmonopolização do saber. Eu me irritava com aquilo. Mas o que é isso? Trocando em miúdos, o que significa desmonopolizar o saber? Até eu sabia que era fazer com que todo mundo se apropriasse do conhecimento, mas como? Porque o saber ficava - e até hoje fica - na mão do terceiro grau e o pessoal de nível médio era considerado sem-saber, estava ali para cumprir ordens apenas. Para o grupo que defendia isso, a enfermagem só teria nível superior, universitário. (a) Amiga de longa data da entrevistada. Coordenadora Geral de Ações Técnicas de Educação Profissional na Saúde, Secretaria de Gestão do Trabalho e da Educação na Saúde, Ministério da Saúde.

(b) Para manter a fidedignidade do depoimento, deste item para frente, o relato passa a ser na primeira pessoa do singular, tendo-se mantido ao máximo o texto original, se não na seqüência, no conteúdo dos temas tratados. 
Fui massacrada pela idéia de defender a formação no nível médio. Porque eu não tinha compromisso com COFEN nem com coisa nenhuma, com nada. Eu só tinha (e tenho) compromisso com uma coisa: com a qualidade do serviço prestado à população. Já que vocês admitiram esse povo, não podem colocar no paredão 150 mil pessoas, não podem. Desemprego em massa? Seria uma loucura. A sociedade iria ficar chocada. Em São Paulo já tinham começado a prender atendentes que estavam ilegais.

Eu participei de uma reunião no Ministério da Saúde que foi a coisa mais trágica que já vi na minha vida. Estávamos eu e o Roberto Nogueira (da área de Recursos Humanos) e o pessoal do sindicato e ficamos no meio da discussão sendo pressionados o tempo todo. Diziam que eu era irreverente... Eu era a Geni, aquela em que todo mundo jogava pedras.

\section{A CHAVE}

Eu continuei trabalhando, sabendo que tinha que derrubar vários paradigmas. Eu queria criar uma escola-função que fosse para onde o aluno estivesse e não uma escola-endereço em que o aluno tivesse que se deslocar do trabalho para ir até ela. Para essa escola-função ia utilizar enfermeiros do serviço com função docente para atuar e uma metodologia que partisse da realidade em que as pessoas estavam. Não podia usar símbolos para passar conhecimento para eles, tinha que ser a própria realidade. Tinha que estabelecer um processo metodológico em que o professor não intermediasse, não ficasse como intermediário entre o conhecimento e o aluno. Não! Tinha que colocar o aluno diretamente junto do objeto de estudo e o docente ficar ao lado ajudando.

Isso parecia uma heresia, ninguém conseguia alcançar. Mas eu não sei porque, eu tinha certeza que ia dar certo. Intuição, sei lá o que era! Como não tinha dinheiro e só tinha problemas, eu fui trabalhando para transformar esse desejo num movimento nacional e usei a técnica de foquismo de Che Guevara. Seria concentrar esforço político em várias cidades do Brasil para ao longo do tempo ir alcançando um movimento nacional. Lembram-se da época do Che Guevara, que ele usava como estratégia de trabalhar diretamente com as pessoas envolvidas? Eu usei essa técnica, eu estava contaminada por essa idéia de foquismo, assim como várias outras pessoas no Brasil. Conforme isso foi crescendo eu fui ampliando a idéia.

Outra coisa que eu também precisava era de um movimento para poder trabalhar contra a hegemonia. A primeira coisa que eu fiz foi ir ao Ministério da Educação conversar com as pessoas que mexiam com a estruturação de escolas. Eu queria fazer uma série de perguntas a elas, principalmente, se eu podia fazer uma escola diferente. Lá tinha uma pedagoga velhinha, daquelas que mexiam com estruturas bem rígidas. Ela era velhinha mesmo. Eu falei: Escuta aqui. Eu posso fazer uma escola diferente? Ela falou: diferente como? Eu: Uma escola que chegue até onde está o aluno e que no regimento permita a descentralização dos cursos. Uma escola que se desloca para onde o aluno se encontra, uma escola que seja flexível, uma escola que trabalhe com a docência não como cargo, mas como função. Ela falou: Se essa escola for aprovada pelo Conselho Estadual de Educação, pode. Eu: Então vou fazer.

Passei vários meses trabalhando com aquela velhinha e com outras pessoas de lá, do Ministério da Educação. Comecei estudando a legislação sobre educação e percebi que no Brasil já tinha esse modelo de escola que era o ensino supletivo. Só que o ensino supletivo não tinha a característica de ir até o lugar do trabalho, o aluno precisava se desvincular do trabalho para fazer o supletivo. Tinha também a proposta de Paulo Freire que era fazer a escola próxima à realidade do aluno. Eu queria uma escola mais flexível do que aquela que o modelo hegemônico preconizava, que era a escola regular. O que eu fiz foi ressignificar com outra visão de mundo o que estava formal e regulado. Assim criei as bases sem fazer ilegalidades, nas brechas da lei. Nessa perspectiva eu buscava uma saída, porque eu sabia que o pessoal que tinha que ser formado não tinha como acessar o conhecimento, fosse pela inadequação metodológica ou fosse pela distância.

E eu fui trabalhando. Nessa época, também, eu já tinha percebido que a educação profissional tinha que estar subordinada não ao MEC, mas ao setor que detém o processo tecnológico, o setor 
da saúde. Isto o MEC não tem. O que o MEC fazia? Pegava todo o pessoal de educação, pegava a técnica e colocava em qualquer objeto de estudo. E eu comecei a ver que não podia ser assim. $\mathrm{O}$ processo educacional tinha que guardar uma relação direta com o objeto de estudo.

Aqueles caras lá da França, liderados por um padre, faziam educação dos excluídos na periferia de Paris, não era nem profissional, era geral. Piaget percebeu isso e ajudou muito a clarear as coisas. Eu tinha um certo preconceito em relação à educação. Por exemplo: eu não gostava, detestava, eu não entendia porque tinha que aprender aqueles verbos e não outros, mais vinculados à vida do educando. Eu falava: por que tem que ser estes verbos, por que não podem ser outros?

Nesse ponto, o texto que eu li da experiência da França me ajudou a compreender que eles estudaram e viram que os excluídos, assim como os não excluídos, também desenvolviam operações mentais para poder trabalhar o conhecimento, para poder conceituar, relacionar, distinguir, chegar a leis e princípios. Para saber conjugar verbos, se tem que fazer várias operações mentais. Operações que na escola de educação geral fazem com a criança logo no começo da aprendizagem. É assim que estudam várias coisas. No geral, o texto falava que o professor tem que ensinar o aluno a pensar. Se ele ensiná-lo a pensar, construindo com ele as operações mentais, ele aprende. Tem que começar pelo mais simples que é escrever e numerar para depois comparar, tirar leis e princípios, conceituar as operações de representação ou de conceituação.

Aí eu pensei: Pôxa, é isso mesmo! No serviço, tem que trabalhar com o aluno no sentido de desenvolver o conhecimento sem ele perder tempo saindo do trabalho. Tem que desenvolver isso: ao mesmo tempo em que ele vai construindo as operações mentais, ele está prestando assistência. Achei a chave e dei um salto. Eu descobri que tinha fazer esse processo de aprendizagem, um ensinoaprendizagem em cima do processo real de trabalho do aluno. O principio pedagógico do trabalho é da Rússia, um dos países socialistas que fazia o seguinte: enquanto o menino estava estudando na escola de segundo grau, ele estava trabalhando nos canaviais, estava vendo o trabalho transformando a realidade. Tudo era feito em cima do processo real de trabalho dele, porque aí ele produzia igual a qualquer pessoa e ao mesmo tempo aprendia. Só que eu queria ir além: transformar o ambiente de trabalho em escola e o próprio processo de trabalho em material para o ensino-aprendizagem.

\section{FALANDO GREGO}

Mas quando comecei a falar sobre isso, parecia que eu falava grego. Ninguém conseguia imaginar do que se tratava. Aí eu pensei: Quer saber de uma coisa? Eu vou fazer o ensino integrado ao serviço, do jeito que eu penso que é. Eu peguei grandes áreas curriculares, que eram relacionadas às grandes competências que eu queria desenvolver no aluno. Dentro dessas áreas curriculares eu construí competências menores e fiz unidades didáticas. Dentro dessas, por sua vez, o aluno tinha que problematizar, era esse o caminho que o aluno tinha que percorrer. Do outro lado, eu botava as dicas para o professor conduzir o processo, ajudar, tirar dúvidas. Ainda escrevi textos síntese. Muita gente ajudou. A Escola de Enfermagem de Minas Gerais me ajudou muito. Foram empregadas práticas entre o pensar e o fazer, tudo junto, com a idéia de que o conhecimento deve ir até onde for necessário. E outra coisa, não tem que ter preconceito, não tem esse negócio de dizer: o auxiliar vai até aqui. Não! Vai até onde for necessário para garantir a qualidade de sua prática.

Acho que acabei fazendo uma verdadeira revolução. Mas uma revolução diferente. Porque o difícil não é fazer a revolução, é reconstruir o país. Para fazer revolução, tem que implantar ódio nas pessoas, tem que exagerar nas coisas. Quando acaba a revolução, tem colocar as coisas nos lugares novamente. Na Nicarágua, por exemplo, quando eu cheguei lá havia ainda muito ódio e isso tinha que ser desfeito senão não conseguiriam governar o país, iriam só continuar fazendo a guerra. Mas isso faz parte do processo dialético. Quando estive em Cuba, perguntei ao Fidel sobre isso e ele falou que faz parte do processo dialético sim, em Cuba foi a mesma coisa. Só que não preciso fazer isso quando se trata de uma revolução educacional. 


\section{A TRAJETÓRIA PROFISSIONAL}

Eu sempre fui da OPAS (Organização Panamericana da Saúde). Todas as minhas propostas saíram dessa Organização, por meio de assessoria ao Ministério da Saúde, às Secretarias de Saúde, às escolas, tanto nos Estados como nos Municípios. No Estado de São Paulo, principalmente na capital, não consegui acabar o processo, não consegui qualificar os atendentes, porque os hospitais privados começaram a formá-los por conta própria. Já em Minas Gerais foi um sucesso. A escola ajudou muito, muita gente participou. As professoras da Escola participaram de tudo desde o começo. O curso de especialização que elas fizeram foi uma experiência muito grande: política, de negociação, de custo, de tudo. Porque toda vez que alguém se expõe, aprende. Elas foram muito corajosas e eu só tenho uma queixa de lá. Elas não disponibilizaram a experiência, não publicaram nada. Fizeram coisas do arco da velha e não publicaram.

A proposta da qualificação dos enfermeiros da rede básica para atuar como docentes na formação do auxiliar de enfermagem começou com Minas, Bahia e Rio Grande do Norte. São Paulo não estava incluído. Eram três escolas de nível superior que iam começar o processo de descentralização desses cursos de educação continuada. Mas na Bahia não vingou e no Rio Grande do Norte também não. Na Bahia faltou liderança. Em Minas foi excelente por causa da liderança. Começou bem, produziram muita coisa, fizeram educação continuada, currículo integrado do auxiliar de enfermagem, mas na hora de fazer o currículo de graduação em enfermagem, não foi para frente. Isto mostra como é difícil o processo de mudança. Porque o processo hegemônico é muito forte na cabeça das pessoas e é um entrave para as mudanças.

\section{SOBRE O PROFAE}

O Profae nasceu num contexto calamitoso. Em São Paulo, os atendentes dos hospitais estavam sendo presos, pelo menos era o que se dizia. Aí o sindicato veio ao Ministro Serra e falou para ele: É lógico que tem que ser o Estado que tem que fazer o papel de intermediação nesse processo. As pessoas não podem ser maltratadas desse jeito. O COFEN colocou na cabeça que agora é lei, que tem que qualificar essa gente e isso tem que ser feito. Se o Estado não entrar para regular esse processo nós vamos ter desemprego em massa. Então o Serra falou: Quem aí no Ministério sabe mexer com nível médio? Então, eu pensei: Agora que vou turbinar o Larga Escala. Montei um grupo e fizemos a proposta. A proposta do Profae foi feita em cima da experiência do Larga Escala, só que com outro nome e modificando algumas coisas. Assim saiu o Profae, o Projeto de Profissionalização dos Trabalhadores de Enfermagem.

No caso do Profae, a gente tinha duas situações: uma que era um grande estoque de leigos trabalhando e colocando em risco a assistência e a outra que era o perigo de perder o próprio emprego. Já eram 150 mil trabalhadores de enfermagem trabalhando sem qualificação. Tinha que trabalhar olhando para trás, para superar as dificuldades já conhecidas e olhar para o futuro, ou seja, trabalhar a sustentabilidade para que o país prosperasse. A sustentabilidade, um dos componentes do Profae dizia respeito a fortalecer o aspecto metodológico das escolas técnicas. Significava captar recursos, fazer projetos, montar laboratórios para não precisar expor o paciente a risco, nem substituir a prática. E mais: desenvolver um sistema de informação para poder monitorar o mercado de trabalho e fazer a avaliação das competências. Porque os órgãos financiadores acreditavam na avaliação das competências. Isso a gente ainda não tinha experiência, nós entramos para aprender.

O Profae, então, tem uma característica muito interessante. Quando foi lançada a proposta de que as instituições deveriam estar respondendo a um edital, já havia recursos financeiros para isto que eram da ordem de 350 mil dólares. Na época, eu falei que a gente ia turbinar porque tinha dinheiro. Aí, fomos trabalhar, inclusive com entidades privadas e credenciar os núcleos de formação. E foi feito também um processo de gerenciamento regional. Essa era outra experiência que estava em andamento que a gente aproveitou. 
Foi nessa época, inclusive, que a Escola de Enfermagem da USP entrou no processo, foi a única vez que a escola entrou institucionalmente. E seria um absurdo não ter entrado. Todo mundo que entrou nisso lucrou. Estava tudo bem organizado. O desafio foi formar 250 mil pessoas em 3 anos. Nunca ninguém tinha feito isso antes. E nós fizemos. Em Washington, o pessoal ficou maravilhado quando contamos essa experiência porque em lugar nenhum no mundo tinha acontecido antes.

Isso, sem contar a formação pedagógica dos enfermeiros no nível de especialização. No país todo, foram formados mais de 12.000 docentes-enfermeiros de melhor qualidade. O próprio currículo integrado já trazia a idéia da competência só que ninguém falava nisso. E ninguém nunca publicou nada também. Eu mesma não tenho nenhum interesse de divulgar nada. Tenho interesse em produzir.

Quanto à história da competência, o que o Profae fala é com muita propriedade. A dificuldade é fazer currículo por competência, que eu acho que só vai sair daqui a cem anos, porque isso não está na área da saúde, mas da educação. Isso fica na mão de pedagogo e pedagogo não entende de saúde. Mas isto é outra história.

\section{O FUTURO DA FORMAÇÃO EM ENFERMAGEM NO BRASIL}

O futuro disso tudo, não sei, porque o grupo ainda não se desenvolveu do ponto de vista político-gerencial para ser mais agressivo na busca de recursos. Ainda há muitos entraves na execução financeira, por exemplo. E tem ainda o processo político nosso que é podre. A bandidagem está instituída. A enfermagem faz parte da sociedade e também sofre as consequiências dessa bandidagem que está aí. Isso tudo ainda atrapalha muito.

O que eu acho é que a experiência do Profae, que é de fortalecer as instituições formadoras, fortalecendo ao mesmo tempo o contingente formado, pode dar passos largos para a formação de $3^{\circ}$ grau. Se na formação da enfermeira, já puder ser utilizada a metodologia problematizadora quem sabe não acelera um pouquinho! Alguma coisa tem que ser feita para melhorar a qualidade da enfermagem brasileira.

Eu não sei... O que eu acho é que não dá para ter pretensão de ficar criando saberes aqui e ali e já querer mudar tudo. É um processo muito lento, muito demorado. Eu levei mais de 20 anos... 